\title{
German Technical Cooperation (GTZ) Supra-regional Project: Promotion of Initiatives to End Female Genital Mutilation (FGM)
}

\author{
Emanuela Finke
}

\section{Female Genital Mutilation in Guinea}

It is estimated that around 130 million women and girls worldwide have undergone female genital mutilation (FGM), with a further 2 million girls thought to suffer the same fate every year. In general FGM is thought to occur mainly in 28 African countries, although the practice has been recognised in Asia and the Middle East. The practice comprises all procedures that involve partial or total removal of the female external genitalia and/or injury to the female genital organs for cultural or any other non-therapeutic reasons.

\section{WHO classification of different types of FGM \\ Type I: Excision of the prepuce, with or without excision of part or the entire clitoris. \\ Type II: Excision of the clitoris with partial or total excision of the labia minora. \\ Type III: Excision of part or all of the external genitalia and stitching/narrowing of the vaginal opening (infibulation). \\ Type IV: Unclassified; includes piercing or incising of the clitoris and/or labia, cauterisation, scraping, or cutting of vaginal tissue etc.}

These operations are all irreversible. Acute complications include death, haemorrhage, shock, infection and severe pain. In addition, women can suffer severe longterm damage to their reproductive and sexual health, risk HIV infection, and are often left with psychological scars.
In Guinea, FGM is widely practised through-out the country with only slight differences in prevalence between ethnic groups or different regions. The most widespread form of FGM is Type II, followed by Type I and Type IV. The age at which girls undergo FGM ranges from several months to 18 years, with an average age of 9 to 10 years. Preliminary results of the November 1999 Demographic and Health Survey (DHS) indicate a prevalence of more than $98 \%$ among women 15 to 49 years of age. However, recent evidence seems to suggest that FGM may be in decline. Indeed, according to a survey conducted in 1997 in Upper and Middle Guinea, the probability of girls and women having undergone FGM in that region declined from $100 \%$ to $86 \%$ between 1984 and 1997.

FGM remains a highly controversial issue in the social, religious and political arenas. However, for many years non-governmental organisations (NGOs) have strongly criticised and campaigned against FGM. Moreover, it has been suggested that young men and women are increasingly aware of the negative consequences the practice has on women's health.

In 1989, a governmental declaration highlighted the Guinean constitution's guarantee of the right to physical integrity, and used this to condemn harmful traditional practices such as FGM. Building on this, a law to promote reproductive health was passed in 2000 that specifically protects women and men from all forms of torture and cruel treatment affecting the body and in particular - the reproductive organs (Art. 6). This legislation is then complemented by a 2001-2010 national action plan against FGM, that has been developed 
through cooperation between the Ministry for Social Affairs, national NGOs and international agencies.

\section{Why was the Intergenerational Dialogue implemented?}

The supra-regional project ?Promotion of initiatives to end Female Genital Mutilation (FGM)? supports governmental, as well as non-governmental organisations, working to end FGM in East and West African countries. It provides technical assistance to its partners in implementing their programmes and activities. The project also helps identify promising approaches and practices that stimulate a process of reflection about traditional attitudes to FGM and help foster relevant behavioural change.

Since 1999, the project has been providing financial and technical support to several NGOs in Guinea. Through training and networking with partners, the coordination team has supported the monitoring and evaluation of different approaches, and has identified questions and difficulties - as well as the achievements - encountered by it's partners.

In 2000, the partner NGOs launched the listening and dialogue' approach among their target groups. They organised 'discussion days' with them, separating different age groups and the two sexes. By training moderators from the same community as the participants, they created the best possible conditions for facilitating a true exchange. Rather than aiming to educate and inform target groups, the new approach sought to ask questions, listen, and to facilitate frank discussions based on mutual respect, in which the responses were neither right nor wrong.

All colleagues in the associations and the coordination team were astounded by the enthusiastic response of the population, the active participation in the 'discussion days', and the frank discussions and honest testimonies. The most important finding was that the persistence of the practice of FGM is not due to a lack of informa-tion. In fact the target groups are well informed about the harmful effects of the practice, and are aware of the various implications of a change of behaviour. Instead, individuals weigh the advantages against the disadvantages.

Currently, many actors in the field of behavioural change (FGM, HIV / AIDS) are asking themselves why information campaigns which increase knowledge among the target groups do not always change deeply rooted behaviours within the population. The 'listening and dialogue' method encourages discussion on the ambivalences and dilemmas which accompany the process of adapting attitudes and behaviours to today's changing world.

One result of the discussions with young women, was the idea of the Intergenerational Dialogue. In several regions, the young women who had benefited from the frank and sincere atmosphere of the discussion days, asked the associations to organise similar discussions between themselves, their mothers and their grandmothers.

The Intergenerational Dialogue method that was developed in response to this request, fits in neatly with the project's approach hitherto. The dialogue enables young and old to reflect on their own values, traditions and aspirations, and to weigh up in their own time under what conditions and in what manner changes should come about.

\section{Stakeholders and their roles}

GTZ NGO partners such as the Fraternité Medical de Guinée (FMG), the Association des Femmes pour l'Avenir des Femmes (AFAF), the Cellule de Coordination sur les Pratiques Nefastes (CPTAFE Labé and Faranah) or the Association Aide pour la Promotion des Femmes (AAPF) are grassroots initiatives working at the community level to address a broad range of topics concerning health, education, empower-ment and community participation. The people and local authorities are familiar with these organisations in each region. Since they have worked there for some time, these NGOs are able to lead open and respectful discussion on the tradition of FGM, its origins and significance to date. Most members of the organisations originate from the same regions and share - despite their different ethnic background - a common understanding of the situation at the community level and an appreciation of its assets and challenges, especially in health, education and sexual and reproductive health (SRH).

The Intergenerational Dialogue is facilitated by NGO staff members who have a compe-tency in adult education and interpersonal communication. During the training of trainers phase, a core group of potential moderators are taken through the whole cycle of 
exercises. This is an important step towards ensuring that facilitators experience, analyse and reflect upon the different key steps and exercises involved in introducing and guiding participants of both generations through a new, appreciative, form of interpersonal and intergenerational commu-nication.

\section{IGD design}

The Intergenerational Dialogue seeks to create spaces for reflection, for listening and for exchange between young and old women, young and old men and between women and men. It aims at increasing communication across the boundaries of age and sex on sensitive issues such as gender relations, sexual morality or sexual and reproductive health. The methods used during the workshops ensure that each generation has the opportunity to express itself, that the two generations and sexes begin to reflect on their own convictions and that agreements on topics where they can come closer together can emerge.

The programme initially works with men and women separately and tries to bring together different generations of each sex to discuss their experiences. The 20 participants at each workshop (10 young/10 old) are selected on the basis of community recommendations or previous contact with local organisations. Trained local staff members moderate the process and seek to promote understanding within these groups. In order to establish a familiar and comfortable learning environment, the workshops are conducted in the local language of a given area and are held in local facilities. Moreover, as most of the older women and men cannot read or write, written training materials are not used in the workshops.

In essence, the generation dialogue is characterised by the following four steps :

\section{Four Day-Workshop}

(a) Proverbs and Sayings:

Proverbs and religious metaphors are used for the mutual presentations of young and old women/men. Similarities and differences between generations are identified and discussed in small peer groups. In two-person discussions the individuals' curiosity and interest in the issue is stimulated. (b) Curiosity exercise

This exercise seeks to allow the generations to become interested in aspects of the lives of the other generation about which they would otherwise never have inquired.

(c) Areas of power and powerlessness

This exercise aims to highlight the differences in power between the generations and shows that both groups can help empower each other.

(d) Life paths:

Young and old generations use role-play, music and songs to share information about key stages in their life. Contro-versial subjects are raised as the discussion about the differences and similarities between the generations unfolds, and moderators seek to encourage participants to use appreciative forms of dialogue in order to achieve common solutions to these points of dischord.

2. Trial Intergenerational Dialogues in the community:

Assisted by the moderators, participants then try out the new forms of dialogue with their families and in their neighbourhoods. The objectives of this phase are: to involve more members of the community, to adapt the dialogue to the realities of a community and to help the spirit of dialogue to become part of the everyday lives of all participants.

3. Two day follow-up workshop with Gender Dialogue:

A month later, participants meet again in a two day workshop to review and evaluate experience gained in the field. Participants' skills in appreciative communication techniques are streng-thened and ways of sustaining the dialogues planned. On the second day of the follow-up workshop men and women of the same age group discuss topics raised previously in the sex-specific groups. The Gender Dialogue initiates a process of rethinking gender relations between men and women of differing ages. Drawing on their initial experiences with the Intergenerational Dialogue, participants identify "burning" issues they wish to discuss 
with the opposite sex. Each group has the opportunity to prepare and present what they want from the other groups, as well as what they want to contribute to improving intergenerational relations.

\section{Continuing Phase:}

In order to sustain the Intergenerational Dialogue, meetings are organised on a regular basis by the male and female participants. They become the coordinators of the extended IGD at community level. At these meetings, the varous themes which came up at the initial workshops can be explored in more depth and discussed with a variety of persons.

\section{Outcomes of the process}

At times in the process, it seems as though the generations are "worlds apart". For the older generation, traditional customs and religion are seen as the regulating and stabilising factors, that sustain a way of life that is intact and value-oriented. By contrast, young men's depictions of their lives, for example, are characterised by a sense of hopelessness and disappointment that leads to increased risk-taking, fatalism and violence.

In particular, differences between the two generations arise with regard to:

(1) pre- and extramarital sexual relationships

(2) the threat of HIV/AIDS and the necessity of condom use

(3) polygamy and the sexual desires of old men

(4) the lack of moral education

(5) the significance of FGM

(6) the role and presence/absence of fathers

(7) the importance of schooling and education

(8) the value of female subjugation to spouse

(9) intra-family, partner violence

From the point of view of older women, the important themes are:

(1) the value of virginity

(2) the value and honour of women's willingness to suffer

(3) the value of traditional rules of good behaviour

(4) the lack of respect shown toward them by the young women

African Journal of Reproductive Health Vol. 10 No.2 August 2006
(5) their fear of HIV/AIDS

The young women in particular argue that:

(1) married older men should stop buying sexual services of young women

(2) violence against women and girls is unacceptable

(3) the practice of forced marriage or should be abandoned

(4) young men should marry girls who did not undergo excision (FGM)

(5) girls should have the opportunity to go to school

(6) fathers should care more about their children and their education

(7) men should use condoms in order to protect their female partners from HIV/AIDS

(8) women should be able to choose when, and how many, children to have

Agreements emerged around the following issues:

(1) The need to tackle the educational and moral crisis

(2) Ending FGM and adapting girls' moral eduaction

(3) The mutual benefits of intergenerational communication

(4) The importance of a dialogue between the sexes

"A woman's life is nothing but suffering: first circumcision, then childbirth and finally marriage. And marriage is the worst of all because it lasts until the grave."

An elderly woman during a dialogue in a district

"We don't even know what paternal love is..."

Young woman, participant in the Labé dialogue

The older men highlight the following issues:

(1) Importance of traditional rules

(2) Opposition to pre- and extramarital sexual relationships

(3) Reference to the Koran on all moral and behavioural questions

(4) Varying positions on FGM

For the younger men the following topics are important: 
(1) Corruption of moral standards and lack of perspectives

(2) The threat of AIDS and the prejudices of the older men

(3) The problems of polygamy

(4) The absence of fathers

(5) The threat of emerging clans of young men

(6) The problems surrounding the sexual needs of older men

In terms of dialogue between the sexes, women increasingly question male behaviour and insist on a more positive attitude towards women including a call to end the acts of violence perpetrated by men against women and girls, a call to end forced marriages and a demand on older men to take more interest and become more involved in their daughters' education.

\section{Further results...}

As a consequence further generation dialogues are demanded by the population:

(1) Participants of the first female Intergenerational Dialogue were enthusiastic about the experience and wanted their partners or key male family members to experience the dialogues. In consequence, a generation dialogue was conducted for men.

(2) Female participants also stressed the need to discuss sensitive issues with their male counterparts, in order to be able to successfully change matters in private and public life. Thus, the gender dialogue came to life.

(3) One group of participants kept the process going and met regularly to mutually encourage and support communication and conflict resolution in their families.

(4) Older male participants were especially concerned about the obvious disorien-tation and frustration of the young men whose perception of life did not at all correspond to the older men's idealistic view of religion as the framework of daily life. They realised the need for improved and more frequent communi-cation between the age groups.

(5) Ministries and partner NGOs in Guinea are asking GTZ to integrate this approach of interpersonal, intergenera-tional communication into the HIV/AIDS campaign.

\section{Measuring the impact}

In October 2003, a quantitative survey of 40 families of workshop participants in the Faranah region (Upper Guinea) and 40 control families was conducted to find out whether the communication between generations had changed in relation to issues such as sexuality, sexual norms, HIV/AIDS and FGM.

Although slight differences exist in relation to gender and age of the respondents, the evaluation found that the families of workshop participants reported more intergenerational communication. Moreover this communication was characterised by a mutual interest in, and openness towards the problems and needs of other family members.

The Intergenerational Dialogue approach is an alternative to interventions that provide awarenessraising information but fail to stimulate behavioural change. Previous experiences have often sought to achieve an individual impact and, to a lesser extent, an impact on families within a confined geographic area. In contrast, this approach uses a participatory community decision-making or consensus-building process which has shown potential to effect change in urban and rural communities.

\section{Lessons learned}

Lessons learned with the programme so far, show that differences and conflicts reveal opinions about key issues that would otherwise remain unsaid. Therefore, old and young need to become aware of the necessity and potential benefits of a more open form of communication that allows possible solutions to be identified as a group. This is especially within the families, where dialogue is easier after having attended the IGD workshops.

"I thought, at my age, nobody could teach me anything anymore. But these last few days have changed me. In fact I no longer know how to behave. I've got a great deal to think about. I thank you."

El Hadj Fodé, aged 75, dialogue participant and influential person from Labé

African Journal of Reproductive Health Vol. 10 No.2 August 2006 


\section{Efficiency}

While the programme ultimately achieved it's aims, a number of difficulties were encountered during implementation. In particular, the length and size of workshops proved to be quite costly and it was difficult to coordinate the workshops with work or family obligations of some community members. Consequently, GTZ and it's NGO partners in Guinea are working on modules that require fewer participants and are better suited to these demands. For example: shorter workshop sessions that run on an ongoing basis.

Importantly, it was recognised that the success of the workshops relied greatly on the communication skills of the moderator. Therefore, it is important to provide initial and "on-the-job" training for moderators. Moreover, it is important to sustain and support the involvement. of group members so that they can become positive role models within their communities.

\section{Replicability}

Once it has been adapted to the local culture and translated into the relevant local language, the Intergenerational Dialogue is going to be extended to other regions of Guinea. In general, adaption to other contexts should be done together with the designated moderators. The whole workshop cycle should be reviewed: experiencing and analysing the exercises and modifying them where appropriate.

There is also a desire to use the method in other sectoral contexts. Plans to integrate the Intergenerational Dialogue on sexuality, HIV/AIDS and FGM into GTZsupported development measures, are currently underway in the context of health, education and the organisational development of local initiatives.

\section{Sustainability}

The training of trainers and action research, served as an institutional learning tool for the partner organisations. It helped NGO staff to acquire basic research skills to be able to monitor and evaluate their own interventions. Furthermore, partner organisations were provided with support to enable them to conduct action research and to measure the impact of their interventions. This process generated inspiration, motivation and good practices on which to base future work. It also created an experience-oriented basis on which to choose between specific approaches, and promoted learning processes and capacity building.

Since the members of the groups ideally become positive role models within their communities, it is important to not only grasp, but also to maintain, momentum. Ways of continuing and deepening the dialogues between participants and in the families are currently being explored. The newly acquired skills of this Intergenerational Dialogue will hopefully enable the generations to practice, and thereby spread, a new form of appreciative, intergenerational communication.

\footnotetext{
"I've seen a fair amount in my life and taken part in a good deal of projects. But, believe me, what we've started here is really important. We've launched something in the communities which is no longer stoppable."

Madeleine Tolno, aged 60 , project coordination team
}

\section{Documentation}

The Intergenerational Dialogue method has been documented in a video that is available from the GTZ project with English, French and German subtitles.

More information, as well as a module on the method, can be found at: http://www.gtz.de/fgm/english/approaches/gendialog.htm and

http://www.gtz.de/fgm/english/countries/ guinea.htm. 